\title{
Nonlinear dynamics in photonic crystal nanocavity lasers
}

Skovgård, Troels Suhr; Kristensen, Philip Trøst; Frandsen, Lars Hagedorn; Schubert, Martin; Gregersen, Niels; Mørk, Jesper

Published in:

Conference abstract series, CLEO/Europe - EQEC

Link to article, DOI:

10.1109/CLEOE-EQEC.2009.5194800

Publication date:

2009

Document Version

Publisher's PDF, also known as Version of record

Link back to DTU Orbit

Citation (APA):

Skovgård, T. S., Kristensen, P. T., Frandsen, L. H., Schubert, M., Gregersen, N., \& Mørk, J. (2009). Nonlinear dynamics in photonic crystal nanocavity lasers. In Conference abstract series, CLEO/Europe - EQEC (pp. 1-1). IEEE. https://doi.org/10.1109/CLEOE-EQEC.2009.5194800

\section{General rights}

Copyright and moral rights for the publications made accessible in the public portal are retained by the authors and/or other copyright owners and it is a condition of accessing publications that users recognise and abide by the legal requirements associated with these rights.

- Users may download and print one copy of any publication from the public portal for the purpose of private study or research.

- You may not further distribute the material or use it for any profit-making activity or commercial gain

- You may freely distribute the URL identifying the publication in the public portal 


\title{
Nonlinear Dynamics in Photonic Crystal Nanocavity Lasers
}

\author{
T. Suhr, P. T. Kristensen, L. H. Frandsen, M. Schubert, N. Gregersen, J. Mørk \\ DTU Fotonik - Department of Photonics Engineering, Technical University of Denmark, DK-2800 Kgs. Lyngby, Denmark \\ Email address: suhr@fotonik.dtu.dk
}

The recent advances in process technology have made possible the fabrication of nanolasers in photonic crystal cavities, which have large Purcell factors and a predominant coupling to the cavity laser mode [1]. To achieve a seizable output power, it is necessary to fabricate large arrays of this novel type of laser and it is therefore important to understand the coupling effects of these arrayed nanolaser systems in order to optimize the output power and ensure stable operation [2]. Here, we quantify the coupling strength needed for coherent coupling of the laser cavities when taking into account detuning effects and show that the systems display rich nonlinear dynamics.

We model the coupling effects using a tight-binding approach by adding phase-dependent coupling terms to the laser rate equations, which are derived from coupled mode theory. The Purcell enhancement of spontaneous emission is modeled as in ref. [3] by $\left(\beta F_{P}+(1-\beta)\right) B N^{2}$, where $\beta$ is the spontaneous emission factor, $F_{P}$ the Purcell factor, $B$ the bimolecular recombination coefficient and $N$ the carrier density.

The laser rate equations are solved numerically in the time-domain and the steady-state solutions can be represented in phase-space as limit cycles (corresponding to oscillatory steady-states) and points (constant steady-states). Fig. 1a displays a Poincaré map of the steady-state phaseplots for a two-cavity system as a function of the coupling strength, which is defined as the (normalized) overlap between two neighboring cavities. Phase-locking behavior is recognized in the low-coupling regime, whereas the amplitude of the limitcycle increases with the coupling strength and evolves into a complex oscillatory behavior that displays several period doubling bifurcations. The same tendency is seen in work on coupled VCSEL arrays [4].
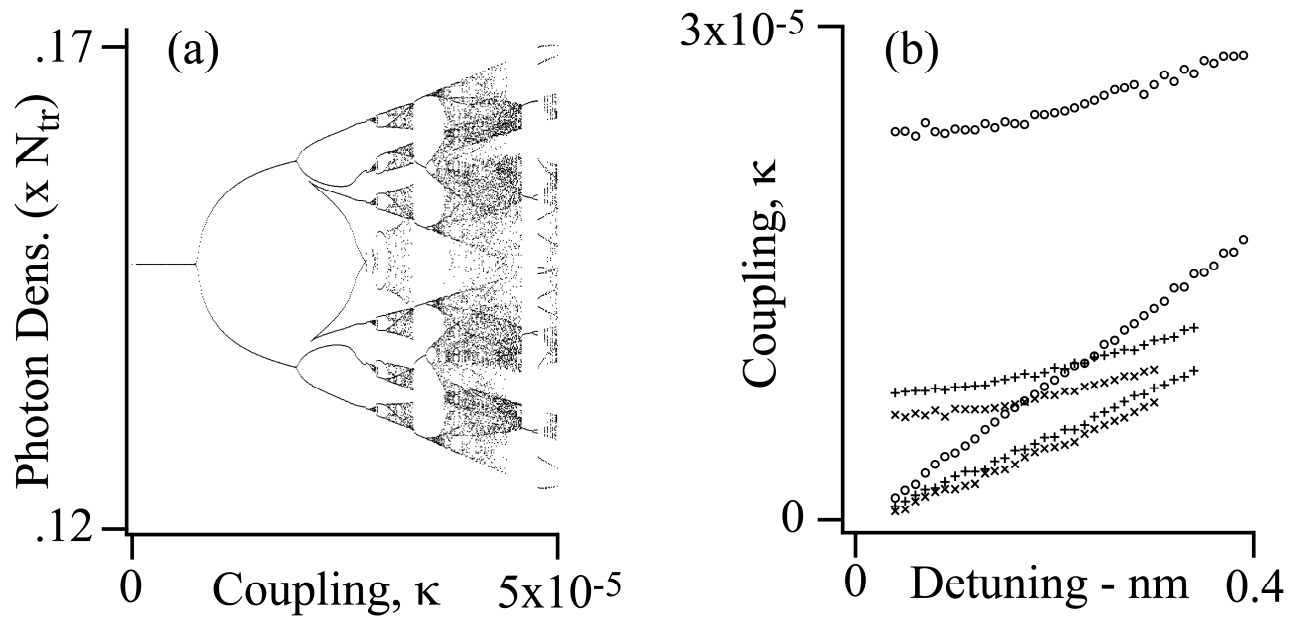

Fig. 1 a) The Poincaré map for a two-cavity system as a function of the coupling strength. b) The upper and lower bound on the phase-locking regime for $\beta=1(\circ), \beta=0.1(+)$ and $\beta=0.01(\mathrm{x})$. In both graphs are used a quality factor of 2000 .

Due to imperfections in the fabrication process, the resonance frequencies of the cavities are often slightly detuned, which can reduce the extent of the phase-locking regime. Our model predicts an additional, lower bound on the phase-locking regime for detuned systems, which is explained as the minimum coupling strength at which the coupling terms can counteract the detuning effects. In fig. $2 \mathrm{~b}$ the dependence of the phase-locking regime on detuning is presented for different values of $\beta$. The figure indicates that a higher value of the $\beta$-factor allows for larger fabrication imperfections, but also that for detuned systems one cannot operate in the phaselocking regime at arbitrary low coupling strengths.

\section{References}

[1] O. Painter, R. K. Lee, A. Scherer, A. Yariv, J. D. O'Brien, P. D. Dapkus and I. Kim, "Two-Dimensional Photonic Band-Gap Defect Mode Laser", Science 284, 1819-1821 (1999)

[2] H. Altug, D. Englund and J. Vuckovic, "Ultrafast Photonic Crystal Nanocavity Laser", Nature 2, 484-488 (2006)

[3] R. S. Tucker, E. K. Lau, M. C. Wu, "Small-Signal Modulation of Purcell-Enhanced Nanocavity Light Emitters", Semiconductor Laser Conference, IEEE 21st International, 181-182 (2008)

[4] S. Riyopoulos, "Coherent Phase Locking, Collective Oscillations, and Stability in Coupled Vertical-Cavity-Surface Emitting Laser Arrays", Physical Review Letters A, 66, 053820 (2002) 